Article

\title{
Preparation of a Low Reducing Effect Sulfonated Alkali Lignin and Application as Dye Dispersant
}

\author{
Yanlin Qin ${ }^{1,2,+}$, Xuliang Lin ${ }^{1,3,+}$, Yaoqin Lu ${ }^{1}$, Siyuan Wu ${ }^{1}$, Dongjie Yang ${ }^{2,3,4}$, Xueqing Qiu ${ }^{2,3,4}$, \\ Yanxiong Fang ${ }^{1, *}$ and Tiejun Wang ${ }^{1, *}$ \\ 1 School of Chemical Engineering and Light Industry, Guangdong University of Technology, \\ Guangzhou 510006, China; ylqin@gdut.edu.cn (Y.Q.); xllin@gdut.edu.cn (X.L.); lyqgduthc@163.com (Y.L.); \\ wusiyuan1201@163.com (S.W.) \\ 2 Guangdong Provincial Key Lab of Green Chemical Product Technology, Guangzhou 510000, China; \\ cedjyang@scut.edu.cn (D.Y.); cexqqiug@scut.edu.cn (X.Q.) \\ 3 School of Chemistry and Chemical Engineering, South China University of Technology, \\ Guangzhou 510000, China \\ 4 State Key Lab of Pulp and Paper Engineering, South China University of Technology, \\ Guangzhou 510640, China \\ * $\quad$ Correspondence: fangyanxiong@gdut.edu.cn (Y.F.); tjwang@gdut.edu.cn (T.W.); Tel.: +86-20-39322231 (T.W.) \\ + These authors contributed equally to this work.
}

Received: 11 July 2018; Accepted: 31 August 2018; Published: 3 September 2018

\begin{abstract}
A novel grafting hydroxypropyl sulfonated and blocking condensed lignin (GSBAL) dye dispersant was prepared based on alkali lignin (AL) by sulfonation and etherification reactions. The significant increase in the sulfonic group content and the molecular weight endow GSBAL with excellent dispersity and stability at high temperatures. More importantly, the unfavorable property of the reducing effect of AL was largely reduced since over $80 \%$ of the phenolic hydroxyl groups were blocked. The functional azo groups in the dye could be mostly retained. The reducing rate of dye with GSBAL was decreased to $6.54 \%\left(25^{\circ} \mathrm{C}\right)$, much lower than $18.62 \%$ for sulfomethylated alkali lignin (SAL) and $15.73 \%$ for sodium lignosulfonate (NaLS). The dispersity and exhaustion of the dye bath with GSBAL dispersant was significantly improved compared with that of a dye bath with SAL and NaLS.
\end{abstract}

Keywords: alkali lignin; hydroxypropyl sulfonation; blocking condensed; reducing effect; dye exhaustion

\section{Introduction}

The textile industry is the largest consumer of disperse dye. Azo dyes contain at least one azo group and account for approximately $70 \%$ of disperse dyes [1]. A disperse dye with poor water solubility cannot be diffused into polyester fiber efficiently [2]. Hence, it is necessary to add dispersant to dye to increase its dispersion, stability, and reduce particle size to promote dyeing efficiency. A typical dosage of dispersant ranges from $75 \%$ to $200 \%$ of dried dye cake mass. The most commonly used dispersants for water-insoluble dyes (most of them are not azo dyes) are sulfonated lignin and naphthalene sulfonates. However, the applications of naphthalene sulfonates are limited due to its high price and toxicity [3].

Two kinds of industrial lignin are byproducts in the papermaking industry. One is lignosulfonates (LS), which come from the sulfite-pulping process and contain water-soluble sulfonic groups. Another is alkali lignin (AL), which comes from the alkali pulping process at elevated temperatures $\left(170^{\circ} \mathrm{C}\right)$. AL is only dissolved in alkali solution due to a lack of hydrophilic groups. Sulfonation is the most effective way to improve the water solubility of AL and thus, broaden its applications. Typically, 
AL was converted into a soluble derivative named sulfomethylated alkali lignin (SAL) at high temperatures. Lignin-based dye dispersants are environment-friendly, sustainable, and renewable.

The reduction of lignin-based dispersants poses obstacles for the application of azo dye, as azo disperse dyes degraded and lost color during the dyeing process [4]. Nevertheless, sulfonated lignin remains attractive due to its superior stability at high temperatures compared with naphthalene sulfonates [5].

The azo dye reduction was inherent to the lignin structural functional group. Extensive studies showed that the easily oxidizable phenol hydroxyls in lignin were the primary cause for reduction [4]. The free phenol hydroxyls in lignin molecules could be easily oxidized to the quinoid structure, while the azo-type dye was converted to hydrazo and amine [5]. The redox reaction between lignin molecules and azo dyes [5,6] is illustrated in Figure 1.

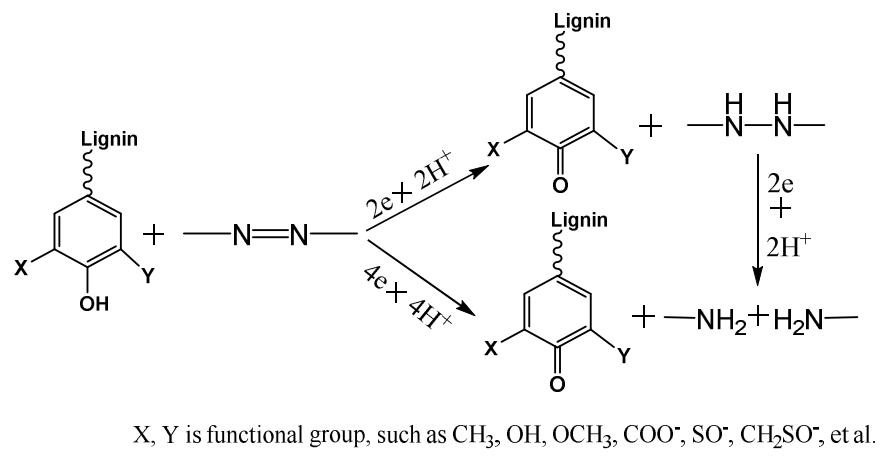

Figure 1. Reduction reaction for azo dye caused by lignin.

The deep color of lignin caused by the quinoid structure further limited its application. An $\mathrm{H}_{2} \mathrm{O}_{2}$ /UV radiation method [7] was attempted to brighten the lignin color; However, the reducing effect of lignin for azo dye remained. As phenolic groups are responsible for the azo dye reduction, blocking phenolic hydroxyl groups in lignin is an effective method to prevent azo dye reduction. Ultrafiltration [8] can remove small molecular lignin dispersants that often have a high hydroxyl group content [9]. Epoxy chloropropane [4], alkylene carbonate [10], and acetylation [11] were used to reduce the phenolic hydroxyl in the lignin molecule [12] but substantially decreased the lignin's water solubility and dispersity without blocking the hydrophilic groups. 1,4-butane sultone (1,4-BS) was applied as a sulfonating and hydroxyl-blocking agent to produce a light-colored lignin-based dispersant from kraft lignin [13]. The prepared dispersant showed good dispersibility and remarkable stain resistance, but kraft lignin's molecular weight was not increased and a lignin reducing effect was not reported.

Our previous studies have revealed that increasing the degree of sulfonation and molecular weight of lignin-based dispersants improved dispersity [14]. However, both sulfonation and polycondensation preferentially take place on the ortho position of the phenolic hydroxyl in AL molecules when preparing SAL [15]. The two competitive reactions in the sulfomethylating process resulted in a trade-off between increasing the sulfonation and molecular weight [16]. AL molecules have a high phenol hydroxyl content owing to depolymerization under highly alkaline and high-temperature conditions during the pulping process. The reduction problem was obvious when using SAL as the dye dispersant. Producing a lignin-based dye dispersant with a low reduction effect, high content of sulfonic groups, and high molecular weight remains a challenge.

_ENREF_11_ENREF_11In this work, a novel lignin-based dispersant was developed by a grafting sulfonation and blocking etherification reaction using alkali lignin as the raw material. The chemical structures and dispersive performance of GSBAL, AL, and NaLS were characterized by FT-IR, NMR, molecular weight, and SEM analysis. The reducing effect of these lignin dispersants for azo dye was 
investigated. Furthermore, the dye exhaustion was also determined to reveal the overall performance of modified lignin-based dye dispersants.

\section{Materials and Methods}

\subsection{Materials}

Alkali lignin (AL, wheat straw alkali lignin, from Tumen Papermaking Co. Ltd., Jilin, China), contains $90 \mathrm{wt} \%$ lignin, $6 \%$ sugars (include glucose, xylose, and arabinose), and $4 \%$ inorganic salts.

Sodium lignosulfonate (NaLS), obtained from Borregaard Co. Ltd. (Shanghai, China). It consists of $91 \%$ NaLS, $4.7 \%$ inorganic salts, and $4.3 \%$ sugars (include glucose, xylose, galactose, and arabinose).

The disperse dye, C.I. disperse blue 79 (one kind of azo dye, $\mathrm{C}_{24} \mathrm{H}_{27} \mathrm{BrN}_{6} \mathrm{O}_{10}$ [17], CAS registry number: 12239-34-8 3618-73-3, the purity is 98\%) from Zhejiang Runtu Co., Ltd. (Hangzhou, China).

Polyester fiber came from RongSheng petrochemical Co. Ltd. (Hangzhou, China).

\subsection{Preparation of Sulfomethylated Alkali Lignin (SAL)}

$\mathrm{AL}(100 \mathrm{~g})$ was dissolved in $300 \mathrm{~mL}$ of alkali solution with $\mathrm{pH}=12$ prepared using distilled water and a $\mathrm{NaOH}$ solution of concentration $2 \mathrm{~mol} \cdot \mathrm{L}^{-1}$. A mixed solution with $10 \mathrm{~g}$ of $\mathrm{Na}_{2} \mathrm{SO}_{3}$ and $10 \mathrm{~g}$ of formaldehyde was added into the AL solution. The mixture was heated to $90^{\circ} \mathrm{C}$ and maintained for $2.5 \mathrm{~h}$. Sulfomethylated alkali lignin (SAL) was obtained after cooling to room temperature. The reaction is shown in Figure 2.

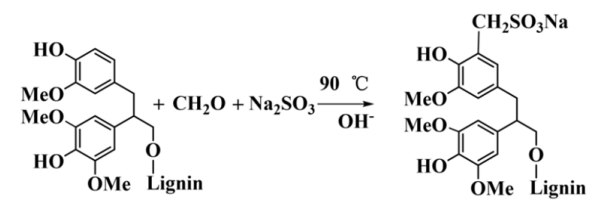

Figure 2. The reaction equation of the preparation of sulfomethylated alkali lignin (SAL).

\subsection{Grafting Sulfonated and Blocking Condensed Alkali Lignin (GSBAL)}

The reaction intermediate sodium 3-chloro-2-hydroxy-propanesulfonate was prepared according to Geng et al. [18]. The following were added to a flask with stirring: $20 \mathrm{~g}$ of $\mathrm{NaHSO}_{3}, 70 \mathrm{~mL}$ of water, and $0.2 \mathrm{~g}$ of $\mathrm{NaOH}$. Epichlorohydrin (16 g) was added slowly (within $30 \mathrm{~min}$ ) at $20-25^{\circ} \mathrm{C}$. Then, the temperature was raised to $45^{\circ} \mathrm{C}$ and maintained for $2 \mathrm{~h}$.

AL (100 g) was solubilized into $100 \mathrm{~mL}$ of distilled water at $\mathrm{pH} 10$ (adjusted with $\mathrm{NaOH}$ solution of $2 \mathrm{~mol} \cdot \mathrm{L}^{-1}$ ). The AL solution was heated to $90{ }^{\circ} \mathrm{C}$. The prepared sodium 3-chloro-2-hydroxy-propanesulfonate was then added into the AL solution, and the reaction proceeded at $90{ }^{\circ} \mathrm{C}$ for $2 \mathrm{~h}$. Afterward, a polymerization reaction was carried out by adding epichlorohydrin $(8 \mathrm{~g})$ dropwise and then maintained for $1 \mathrm{~h}$. After cooling, the GSBAL was obtained. The reaction is shown in Figure 3. Sodium 3-chloro-2-hydroxy-propanesulfonate can also react with $\mathrm{S} \mathrm{PhOH}$ or with $\mathrm{G} \mathrm{PhOH}$ or with both $\mathrm{S}$ and $\mathrm{G} \mathrm{PhOH}$. Due to the complex structure of AL, Figure 3 illustrates a simplified ideal reaction model, in which Sodium 3-chloto-2-hydroxypropane sulfonate reacts solely with $\mathrm{G} \mathrm{PhOH}$.

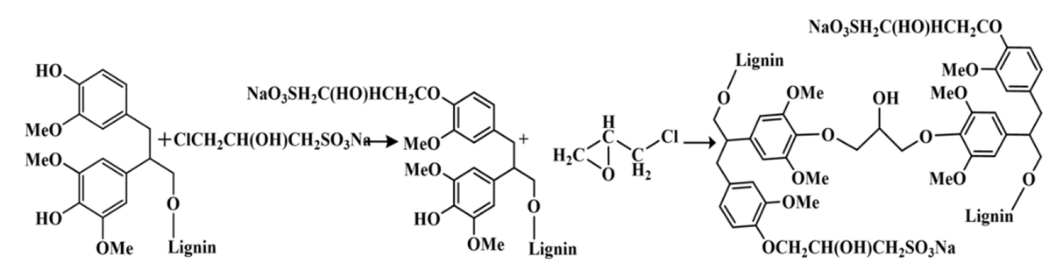

Figure 3. The reaction equation of the preparation of grafting sulfonated and blocking condensed alkali lignin (GSBAL). 


\subsection{FTIR Analysis}

FTIR was carried out using an FTIR Spectrometer (Nicolet Nexus 470, Thermo Nicolet Corporation, Madison, WI, USA). The samples were prepared by mixing $2 \mathrm{mg}$ of dried sample into $200 \mathrm{mg}$ of $\mathrm{KBr}$ to form tablets.

\subsection{HSQC Analysis}

$\mathrm{Al}$ and GSBAL 2D-NMR (HSQC) spectra were recorded using a Bruker spectrometer (DRX-500, Bruker Co., Ettlingen, Germany). A quantity of $60 \mathrm{mg}$ dried AL and GSBAL was dissolved into $0.6 \mathrm{~mL}$ of DMSO- $\mathrm{d}_{6}$ and $0.6 \mathrm{~mL}$ of $\mathrm{D}_{2} \mathrm{O}$, respectively.

\subsection{Molecular Weight Distribution Analysis}

The molecular weight distribution was measured using Waters Styragel columns GPC equipment (Waters 2487 UV absorbance detector, Waters Crop., Milford, MA, USA). Sodium polystyrene sulfonate with different molecular weights was used as the standard for calibration. $\mathrm{A} \mathrm{NaNO}_{3}$ solution of $0.1 \mathrm{~mol} \cdot \mathrm{L}^{-1}$ was used as the mobile phase. All samples were adjusted to $10 \mathrm{mg} \cdot \mathrm{L}^{-1}$ using double-distilled water and filtered through a $0.22 \mu \mathrm{m}$ syringe filter before testing.

\subsection{Sulfonic Group Content Measurement}

The sulfonic group content was determined by the potentiometric titration method using an automatic potentiometric titrator (809 Titrando, Metrohm Corporation, Herisau, Switzerland) [19]. Before titration, the samples were ion-exchanged through the anion exchange resin and cation exchange resin to remove salts and other impurities. A $0.05 \mathrm{~mol} \cdot \mathrm{L}^{-1} \mathrm{NaOH}$ standard solution was used as the titrant. The first-order derivative peak of the titration curve at $\mathrm{pH}$ windows of 5.5-5.8 is the titration end point. The titration temperature was kept at $25^{\circ} \mathrm{C}$. The sulfonic group content can be calculated using Equation (1):

$$
\text { Sulfonic group content }=\frac{\text { mmole of } \mathrm{SO}_{3} \mathrm{H}}{\text { dried sample }(\mathrm{g})}
$$

\subsection{Phenolic Hydroxyl Content Measurement}

The phenolic hydroxyl content was measured using the Folin-Ciocalteu (FC)-reagent method [20]. First, dissolve $50 \mathrm{mg}$ of dried dispersant into $100 \mathrm{~mL}$ water. Thoroughly mix $15 \mathrm{~mL}$ of the prepared sample solution with $1.5 \mathrm{~mL}$ of the FC-reagent. This is followed by adding $5 \mathrm{~mL}$ of $20 \%(w / v) \mathrm{Na}_{2} \mathrm{CO}_{3}$ solution and adjusting the volume to $25 \mathrm{~mL}$ using distilled water. The final mixture was kept stirring for $2 \mathrm{~h}$ at $30^{\circ} \mathrm{C}$. A UV-Vis spectrophotometer (UV-2450, Shimadzu Co., Tokyo, Japan) was used to measure the absorption of the final mixture at $760 \mathrm{~nm}$ to determine the phenolic hydroxyl content. Vanillin solutions with different concentrations were used for calibration.

\subsection{Preparation of Dye Suspension}

A total of $7.5 \mathrm{~g}$ of dried dispersant and $5 \mathrm{~g}$ of dried dye filter cake were ball-milled using a planetary ball mill loaded with $200 \mathrm{~g}$ agate beads (QM-3SP2, Nanjing University Instrument Co., Nanjing, China). The solid content of the mixture was adjusted to $30 \mathrm{wt} \%$ and $\mathrm{pH}$ was maintained at 5.5 by adding $\mathrm{HAc} / \mathrm{NaAc}$ buffer solution. The dye suspension was obtained by milling for $6 \mathrm{~h}$ at a rate of $400 \mathrm{r} \cdot \mathrm{min}^{-1}$.

\subsection{Dye Exhaustion Measurement}

The polyester fibers were pretreated before dying. An acetate buffer solution of $\mathrm{pH} 5.0$ was prepared by using $0.05 \mathrm{~mol} \cdot \mathrm{L}^{-1}$ of anhydrous sodium acetate and $0.0275 \mathrm{~mol} \cdot \mathrm{L}^{-1}$ of acetic acid. Fibers were washed four times using hot water at $95^{\circ} \mathrm{C}$ and maintained for $45 \mathrm{~min}$ for each washing, and then soaked in the prepared buffer solution for 1 day before being dried for dyeing. 
An intelligent controlled GRY-12 dyeing equipment (Quanrun Machinery Co. Ltd., Wuxi, China) was employed to carry out the dyeing process. The dye bath was obtained from the dye suspension (the preparation of which was described in Section 2.9) by diluting to $0.5 \mathrm{wt} \%$ using distilled water and adjusting the $\mathrm{pH}$ to $5.5 \mathrm{using}$ an $\mathrm{HAc} / \mathrm{NaAc}$ buffer solution. A total of $2.0 \mathrm{~g}$ of pretreated dried fibers were added into the $200 \mathrm{~mL}$ dye bath (liquid/solid ratio $=100: 1$ ). The dyeing temperature was first raised from 20 to $130{ }^{\circ} \mathrm{C}$ at $2{ }^{\circ} \mathrm{C} \mathrm{min}-1$ and maintained at $130{ }^{\circ} \mathrm{C}$ for $45 \mathrm{~min}$ followed by cooling to $80{ }^{\circ} \mathrm{C}$ at $4{ }^{\circ} \mathrm{C} \cdot \mathrm{min}^{-1}$.

A UV spectrometer (Shimadzu Corp., Tokyo, Japan) was used to determine the dye exhaustion by testing the absorbance of $0.02 \mathrm{~g} \cdot \mathrm{L}^{-1}$ of dye bath (diluted to with acetone) at $580 \mathrm{~nm}$. The dye exhaustion was calculated using Equation (2).

$$
\varepsilon=\frac{A_{i}-A_{f}}{A_{i}} \times 100 \%
$$

where $\varepsilon$ is the dye exhaustion, $A_{i}$ and $A_{f}$ are the absorbance of the dye bath without and with dyeing process, respectively.

\subsection{Scanning Electron Microscope (SEM) Images Measurement}

The prepared dye bath $(200 \mathrm{~mL})$ in Section 2.10 was placed into the dyeing vessel. The experiment process described in Section 2.10 was implemented without using polyester fiber. The SEM images of samples were recorded with SEM instrument (Zeiss Netherlands BV, Sliedrecht, The Netherlands).

\subsection{Reducing Rate of Dispersant on Azo Dye}

The reducing property of the dispersant on disperse blue 79 was measured at 25 and $130{ }^{\circ} \mathrm{C}$ respectively by a UV spectrophotometer (UV-2450, Shimadzu Corp., Tokyo, Japan). The temperature of the dye bath was kept at 25 and $130{ }^{\circ} \mathrm{C}$ for $45 \mathrm{~min}$, respectively. Then, the dye bath was diluted to $0.02 \mathrm{~g} \cdot \mathrm{L}^{-1}$ with acetone to prepare a dyestuff composition. Disperse blue 79 (dye filter cake) was dissolved into acetone to prepare a dye solution of $0.02 \mathrm{~g} \cdot \mathrm{L}^{-1}$ not containing dispersant as the control sample at 25 and $130^{\circ} \mathrm{C}$. The azo percentage is calculated by Equation (3).

$$
\text { Dye reducing rate } \%=\frac{A_{0}-A_{t}}{A_{0}} \times 100
$$

where, $A_{0}$ is absorbance of the dye in acetone at $\lambda_{580}, A_{t}$ is the absorbance of a dye bath in acetone at $\lambda_{580}$.

\section{Results and Discussion}

\subsection{FTIR Analysis}

FTIR spectra of AL and GSBAL were recorded and represented in Figure 4. The semi-quantitative method of FTIR was carried out to reveal the hydroxy structural changes of lignin [21,22]. The areas of bands at $1503 \mathrm{~cm}^{-1}$ observed in both samples corresponding to aromatic ring stretching vibrations [22] were calculated. The reactions occurred on the phenolic hydroxyl group, which would not affect the aromatic ring structure of lignin [21,22]. The peak at $1503 \mathrm{~cm}^{-1}$ could be regarded as the reference peak. The band at $3420 \mathrm{~cm}^{-1}$ related to the aromatic and aliphatic $\mathrm{OH}$ group in lignin [23]. The ratio of the peak area at $3420 \mathrm{~cm}^{-1}$ and $1503 \mathrm{~cm}^{-1}$ (A3420/A1503) of AL and GSBAL was 61.32 and 23.46, respectively. A3420/A1503 of GSBAL essentially decreased compared with AL, suggesting that most of the $\mathrm{OH}$ groups were blocked by epichlorohydrin. The peaks at $2935-2938 \mathrm{~cm}^{-1}$ assigned to the stretching vibration of $\mathrm{CH}_{2}$ or $\mathrm{CH}_{3}$ [24], became intense in GSBAL, which indicated that the hydroxy-propane sulfonate contained methyl and that the methylene group was grafted into lignin. The band at $1330 \mathrm{~cm}^{-1}$ is related to the syringyl ring breathing with $\mathrm{C}-\mathrm{O}$ stretching vibration [25]. 
The peaks at $1192 \mathrm{~cm}^{-1}$ and $1048 \mathrm{~cm}^{-1}$ are attributed to the asymmetric and symmetric stretching vibration of the sulfonic group from GSBAL [26], respectively. The signal at $850 \mathrm{~cm}^{-1}$ can be assigned to a $\mathrm{C}-\mathrm{H}$ out-of-plane deformation vibration at the 2,3 , and 6 positions of the benzene ring [27].

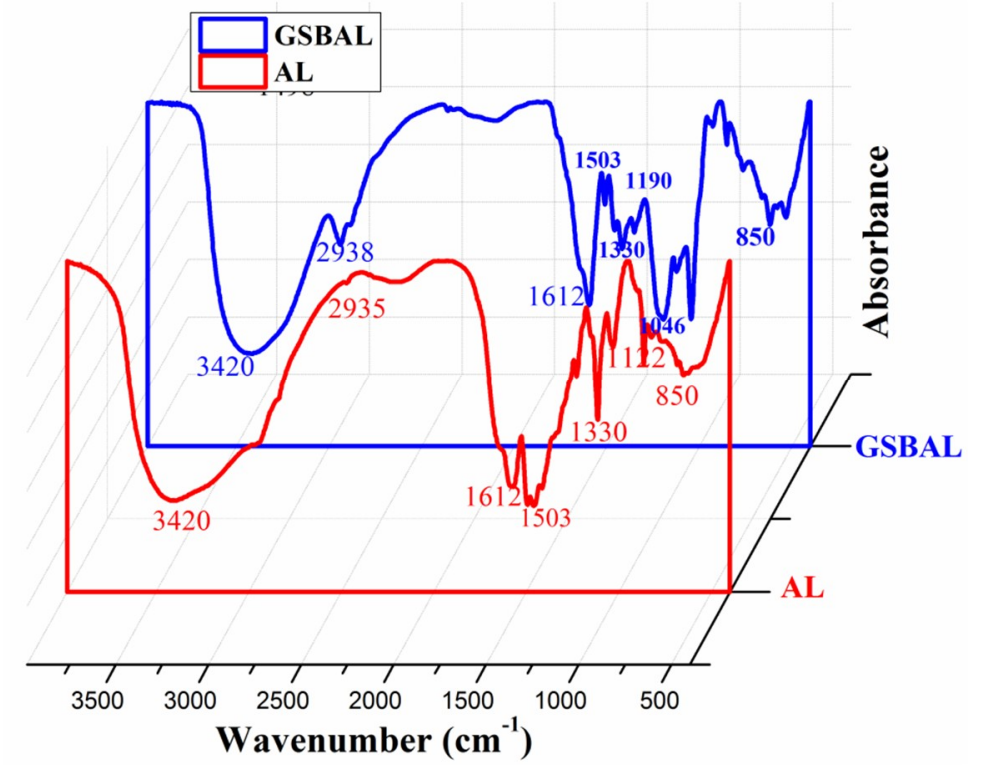

Figure 4. FTIR spectra of alkali lignin (AL) and GSBAL.

\section{2. ${ }^{1} \mathrm{H}^{13} \mathrm{C}$ Correlation NMR Spectrum (HSQC) of AL and GSBAL}

To further investigate the structure of AL and GSBAL, ${ }^{1} \mathrm{H}-{ }^{13} \mathrm{C}$ HSQC spectra of AL and GSBAL are shown in Figure 5, and the signal assignments are listed in Table 1. A wheat straw alkali lignin (AL) spectrum [28], which was recorded in our previous work, is shown as a comparison in Figure 5a.

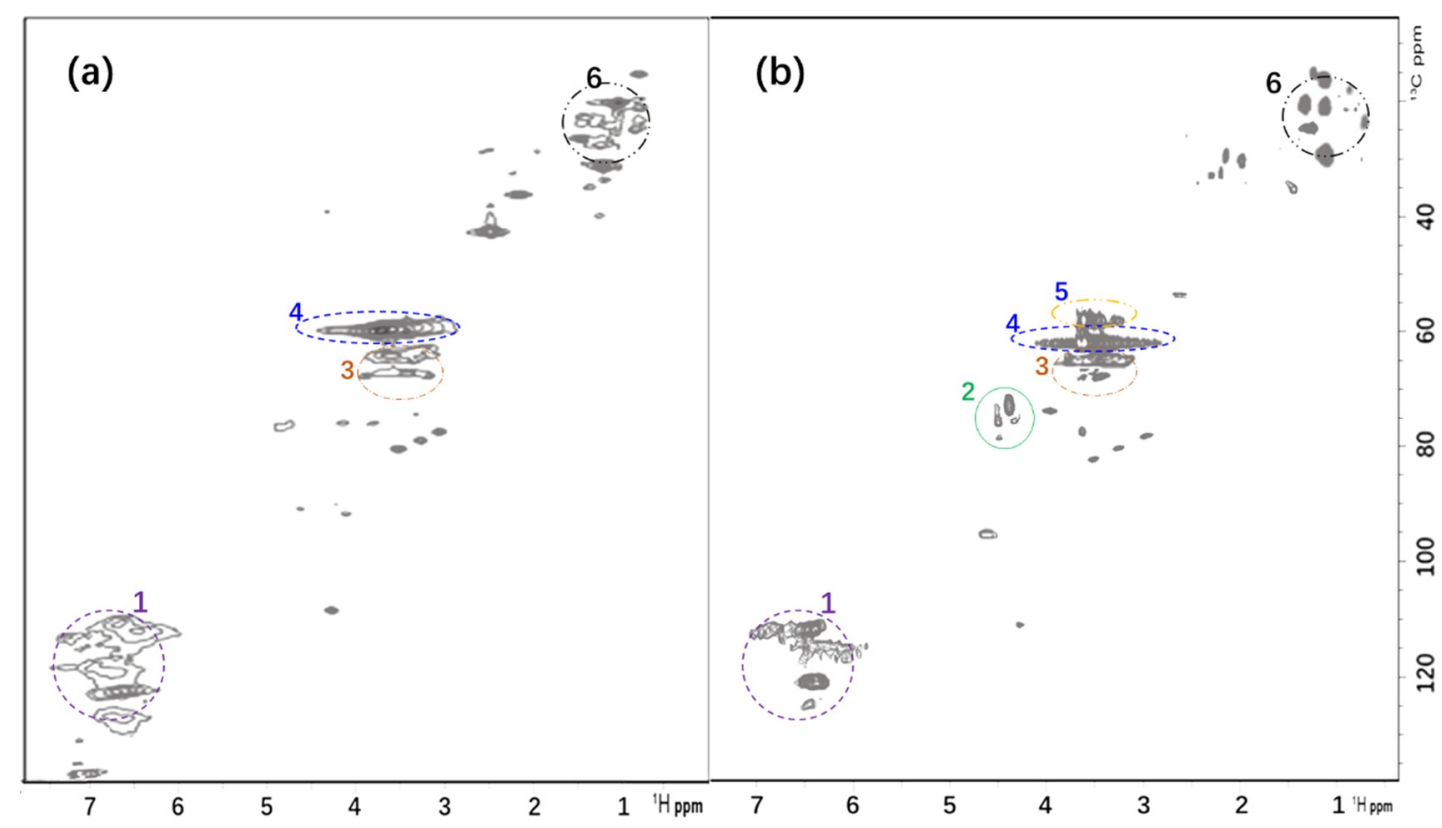

Figure 5. HSQC 2D-NMR analysis of (a) AL, reproduced with permission from [28]. Copyright Taylor \& Francis 2013; and (b) GSBAL (signal assignment of marked numbers is shown in Table 1). 
The regions at $6.2-7.5 / 102-125 \mathrm{ppm}$ of the GSBAL spectrum are attributed to aromatic $\mathrm{H}-\mathrm{C}$ correlation. The region at 4.4-4.9/68-80 ppm is assigned to sulfonated side-chains H-C correlation. Meanwhile, the appearance of new signals at 3.0-3.6/53-57 ppm is attributed to methylene in the grafted hydroxypropyl sulfonate. This indicated that 3-chloro-2-hydroxy-propanesulfonate was successfully grafted into the AL molecule. The signal intensity at $3.0-4.4 / 56-62 \mathrm{ppm}$ in both spectra is related to methoxy groups.

Table 1. Signal assignment of HSQC NMR spectra of AL and GSBAL.

\begin{tabular}{ccc}
\hline Marked Number & $\boldsymbol{\delta}_{\mathbf{H}} / \boldsymbol{\delta}_{\mathbf{c}} \mathbf{p p m}$ & Assignment \\
\hline 1 & $6.2-7.5 / 102-125$ & Aromatic ${ }^{1} \mathrm{H}-{ }^{13} \mathrm{C}[29]$ \\
2 & $4.4-4.9 / 68-80$ & ${ }^{1} \mathrm{H}-{ }^{13} \mathrm{C}$ correlation in sulfonated chain $\left(-\mathrm{CH}_{2} \mathrm{CH}(\mathrm{OH}) \mathrm{CH}_{2} \mathrm{SO}_{3} \mathrm{Na}\right)[29,30]$ \\
3 & $3.4-3.7 / 62-72$ & Aliphatic oxygenated ${ }^{1} \mathrm{H}-{ }^{13} \mathrm{C}[31]$ \\
4 & $3.0-4.4 / 56-62$ & Methoxyl [32] \\
5 & $3.0-3.6 / 53-57$ & Methylene (part of sulfonated chain) $[33]$ \\
6 & $0.5-1.5 / 15-30$ & Aliphatic non-oxygenated ${ }^{1} \mathrm{H}-{ }^{13} \mathrm{C}[31,32]$ \\
\hline
\end{tabular}

\subsection{Molecular Weight and the Functional Group}

The weight-average $\left(M_{w}\right)$, number-average $\left(M_{n}\right)$ molecular weights and the polydispersities $\left(M_{w} / M_{n}\right)$ together with the contents of sulfonic group and phenolic hydroxyl group dispersants are listed in Table 2. The $M_{w}$ was increased from 4920 Da for AL to 11,350 Da for GSBAL. It indicates that epichlorohydrin reacts with phenolic hydroxyl groups of GSBAL and improves the $M_{w}$ more effectively than SAL. The $M_{w}$ of NaLS was 10,250 Da, which was higher than SAL. This is due to the removal of the low molecular weight fraction by ultrafiltration. Polydispersity, see Table 2, indicates the distribution of the polymer's molecular weight. The polydispersity was decreased from 2.59 for AL to 1.93 for GSBAL, indicating that a blocking condensed process using epichlorohydrin increased the molecular weight with a more uniform distribution than SAL.

GSBAL had a higher sulfonic and a much lower phenolic hydroxyl content than those of NaLS and SAL. The phenolic hydroxyl group was $0.42 \mathrm{mmol} \cdot \mathrm{g}^{-1}$, substantially lower than $2.27 \mathrm{mmol} \cdot \mathrm{g}^{-1}$ of $\mathrm{AL}$, suggesting that more than $80 \%$ of these were blocked. It can be inferred from the results that the copolymerization and grafting mainly took place on phenolic hydroxyl groups. SAL had low sulfonic and high phenolic hydroxyl contents, indicating that sulfonation was more competitive than polycondensation.

Table 2. Molecular weight data and functional groups of dispersants.

\begin{tabular}{cccccc}
\hline Dispersants & $\boldsymbol{M}_{\boldsymbol{w}}$ (Da) & $\boldsymbol{M}_{\boldsymbol{n}} \mathbf{( D a )}$ & $\boldsymbol{M}_{\boldsymbol{w}} / \boldsymbol{M}_{\boldsymbol{n}}$ & $\begin{array}{c}\text { Sulfonic } \\
\left(\mathbf{m m o l} \cdot \mathbf{g}^{-\mathbf{1}} \mathbf{)}\right.\end{array}$ & $\begin{array}{c}\text { Phenolic Hydroxyl } \\
\left(\mathbf{m m o l} \cdot \mathbf{g}^{\mathbf{- 1}} \mathbf{)}\right.\end{array}$ \\
\hline AL & 4920 & 1900 & 2.59 & - & 2.27 \\
NaLS & 10,250 & 4780 & 2.14 & 1.36 & 1.88 \\
SAL & 6140 & 2200 & 2.79 & 1.14 & 2.16 \\
GSBAL & 11,350 & 5880 & 1.93 & 2.21 & 0.42 \\
\hline
\end{tabular}

\subsection{Dispersion Performance}

The dye bath exhibited stability to high temperatures during dyeing to ensure excellent polyester fiber dyeing. Dye with smaller particle sizes in the dye bath presented better stability, and the dyeing efficiency was reported [33]. The morphology of the particles of the dye bath at 25 and $130{ }^{\circ} \mathrm{C}$ were measured and are shown in Figure 6. 


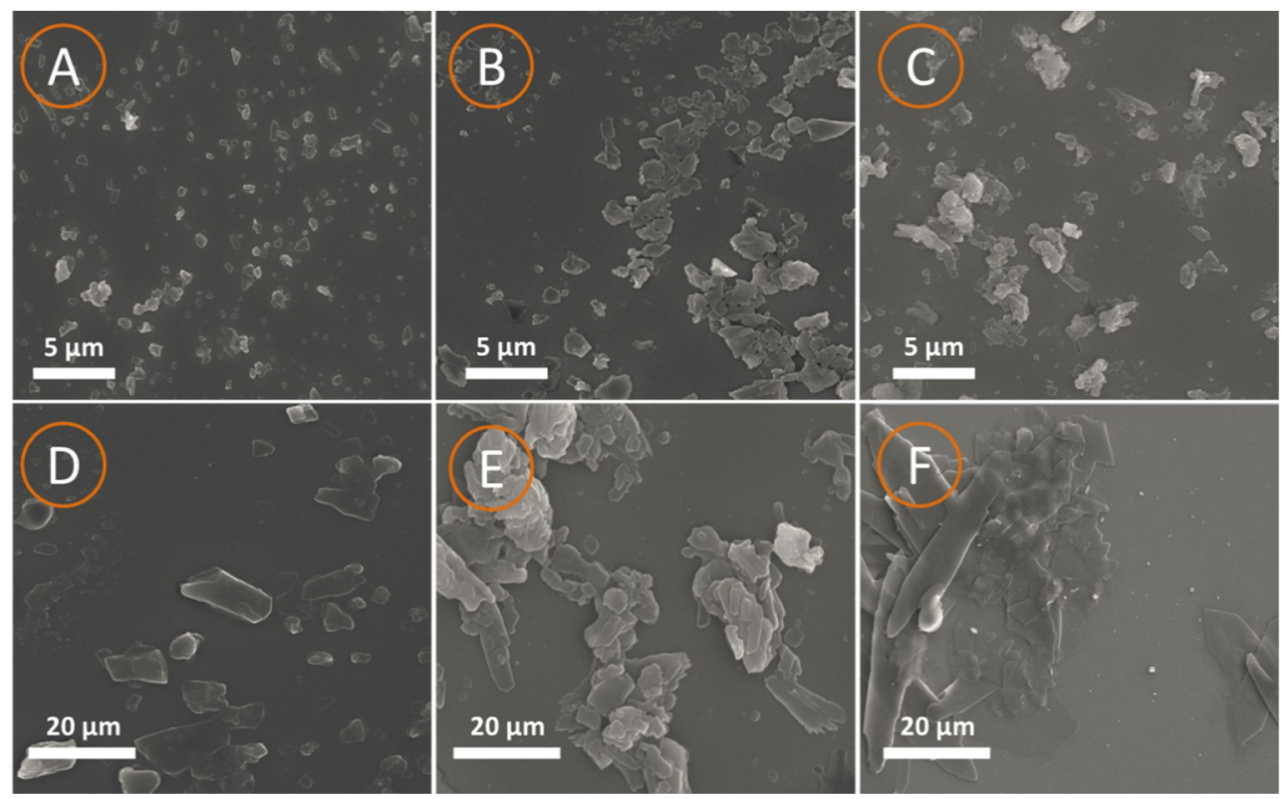

Figure 6. SEM images of dye bath with different dispersant (A) GSBAL at $25{ }^{\circ} \mathrm{C}$; (B) sodium lignosulfonate (NaLS) at $25{ }^{\circ} \mathrm{C}$; (C) sulfomethylated alkali lignin (SAL) at $25^{\circ} \mathrm{C}$; (D) GSBAL after $130{ }^{\circ} \mathrm{C}$; (E) NaLS after $130{ }^{\circ} \mathrm{C}$; (F) SAL after $130{ }^{\circ} \mathrm{C}$.

The shape of the dye particles in a bath with GSBAL, NaLS, and SAL were all flake-like. At $25^{\circ} \mathrm{C}$, all three dispersants performed well in dispersing dye and grinding effects. However, different degrees of aggregation occurred at $130{ }^{\circ} \mathrm{C}$ using different dispersants, see Figure 6D-F. The size of the dye particles was only slightly increased to $9 \mu \mathrm{m}$ using GSBAL. The particles of dye were substantially aggregated to approximately 36 and $42 \mu \mathrm{m}$, respectively, using NaLS and SAL. These results suggest that dye dispersed using GSBAL had better dispersibility and high-temperature stability than dye dispersed using NaLS and SAL.

GSBAL with higher molecular weight and a longer hydroxypropyl chain showed good dispersion by forming a stronger steric hindrance to keep the aqueous dye suspension stable under a high-temperature environment [14]. In the GSBAL molecule, phenolic hydroxyls were blocked while the aliphatic hydroxyl groups were introduced. Hydroxyl groups could be helpful by forming hydrogen bonds between a hydroxyl and the dye to stabilize dye particles in the dye bath [31]. This is an additional innovation of this work compared with other methods for reducing phenolic hydroxyls, such as oxidizing, and the acetylation process. Furthermore, the high degree of sulfonic groups in GSBAL using a graft sulfonation process also provided a strong electrostatic repulsion, increasing the stability of the dye bath [34].

\subsection{Reducing Effect of Dispersant on Azo Dye}

The absorbances at $590 \mathrm{~nm}$ of the dye bath solutions using different dispersants are shown in Figure 7. The dye reducing rates are presented in Figure 8. The absorbance of the dye bath solution increased with the decrease of phenol hydroxyl groups in the dispersants. Dispersion using GSBAL achieved the highest absorption among all the dispersants with similar color to the control sample.

Although the dye reducing effect was aggravated by heating, the reducing rate of $9.79 \%$ of GSBAL $\left(130^{\circ} \mathrm{C}\right)$ was still much lower than $19.87 \%$ of NaLS and $22.05 \%$ of SAL. SAL had the highest reducing rate, ascribed to the sulfomethylated lignin, which had more phenolic hydroxyl groups than lignosulfonate [17]. 


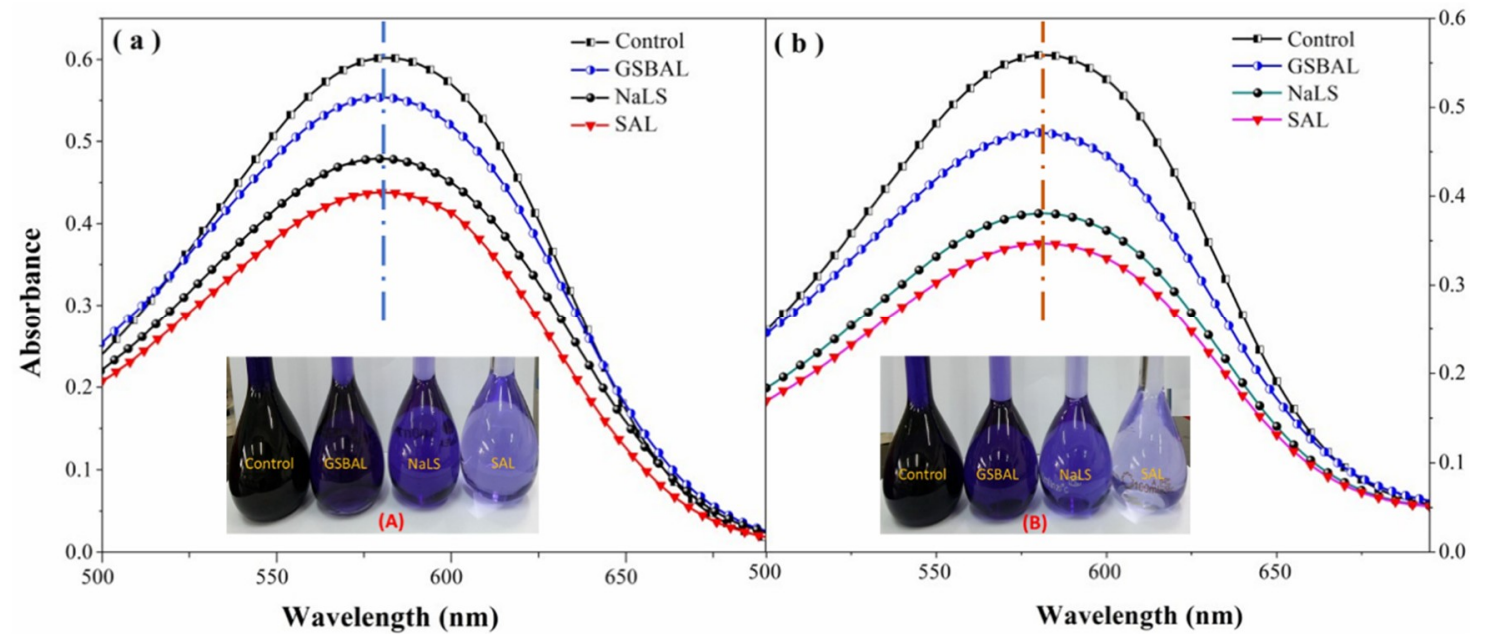

Figure 7. The absorbance of disperse dye baths with different dispersants: (a) $25^{\circ} \mathrm{C}$, (b) $130{ }^{\circ} \mathrm{C}$; the dye concentration in each dye bath was $0.008 \mathrm{~g} \cdot \mathrm{L}^{-1}$, and dispersant (GSBAL, NaLS, and SAL) concentration was $0.012 \mathrm{~g} \cdot \mathrm{L}^{-1}$, respectively.

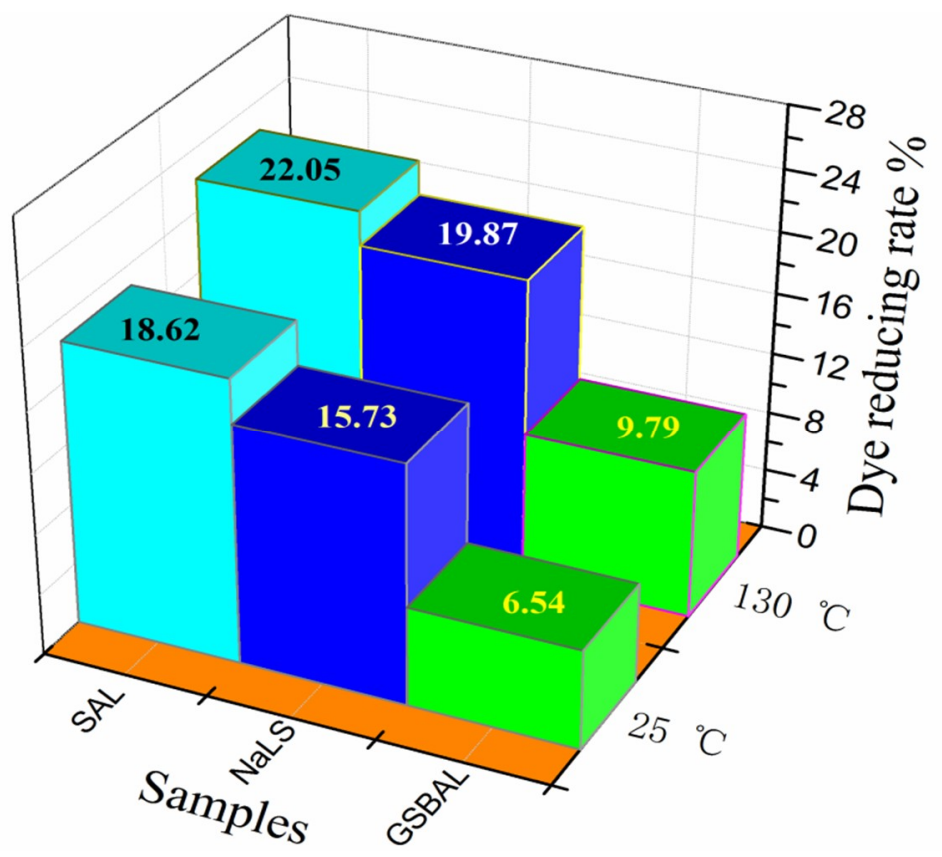

Figure 8. The reducing rate of dispersant at $25^{\circ} \mathrm{C}$ and $130^{\circ} \mathrm{C}$.

\subsection{Dye Exhaustion}

The exhaustion results of disperse dye (C.I. disperse blue 79) are presented in Figure 9. The exhaustion rate of the dye bath with GSBAL reached the highest level of $85.10 \%$, attributed to the higher content of effective dyes in the dye bath during heating as a result of the low reducing rate on disperse azo dye. The dyeing process of disperse dye consists of two steps [35]: The dissolution and redissolution of disperse dye adsorbed onto the fiber surface, followed by the diffusion of absorbed dye into the interior of fibers. The dye particles with GSBAL had better dispersion stability and high-temperature stability. 


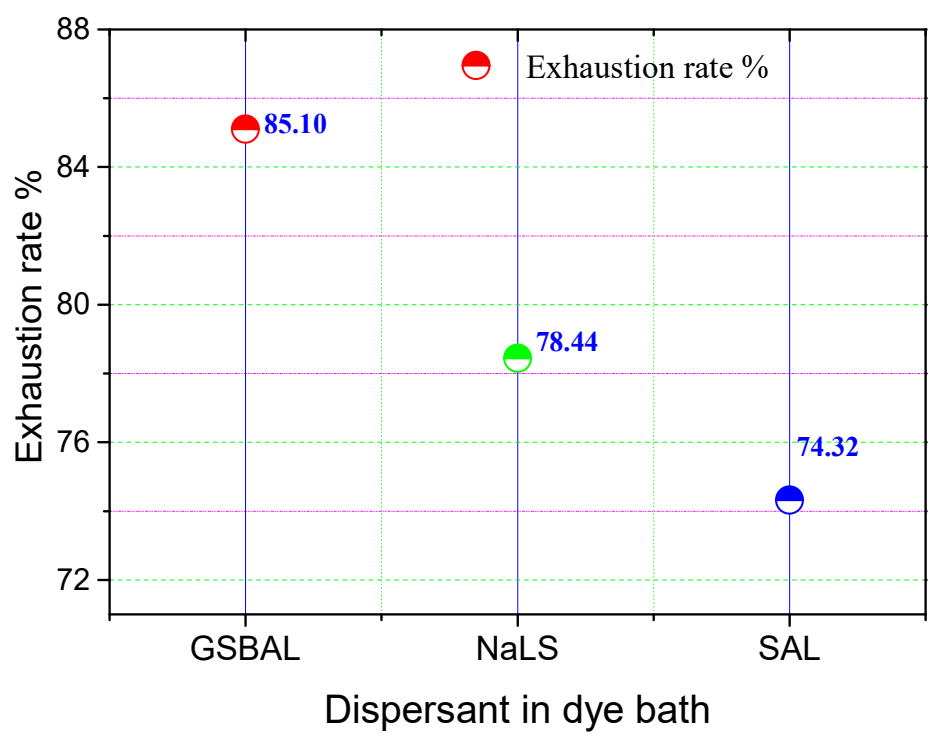

Figure 9. The exhaustion rate of dye baths with different dispersants.

\section{Conclusions}

A novel lignin-based dye dispersant GSBAL was successfully prepared using alkali lignin by grafted-sulfonation with 3-chloro-2-hydroxy propyl sodium sulfonic acid and etherification with epichlorohydrin. The high sulfonic group content and high molecular weight of GSBAL with low phenolic hydroxyl group content exhibited good dispersity, and an ultra-weak reducing effect on disperse azo dye. Hence, GSBAL represented a high exhaustion.

Author Contributions: Y.Q., D.Y., X.Q. and T.W. conceived and designed the experiments; Y.L. and S.W. conducted IR and phenolic hydroxyl content measurement experiments, and analyzed IR spectra; X.L. performed the HSQC analysis and investigated disperse experiments; Y.F. analyzed and interpreted TEM data; Y.Q. wrote the paper.

Funding: This research was funded by the National Natural Science Foundation of China (220413566), Guangdong Province Office of Education Youth Innovation Personnel Training Project (262524146) and Guangdong Provincial Key Lab of Green Chemical Product Technology (GC201802).

Acknowledgments: Authors are grateful to J.Y. Zhu, Hongdan Zhang, Qian Yong, helping us improve the writing and Fengxia Yue provided the assist for NMR analysis. We also want to acknowledge support from the research fund program of National Natural Science Foundation of China (220413566), Guangdong Province Office of Education Youth Innovation Personnel Training Project (262524146) and Guangdong Provincial Key Lab of Green Chemical Product Technology (GC201802).

Conflicts of Interest: The authors declare no conflict of interest.

\section{References}

1. Zhao, X.; Hardin, I.R.; Hwang, H.-M. Biodegradation of a model azo disperse dye by the white rot fungus Pleurotus ostreatus. Int. Biodeter. Biodegr. 2006, 57, 1-6. [CrossRef]

2. Koh, J. Dyeing with Disperse Dyes, In Textile Dyeing; IntechOpen: Rijeka, Croatia, 2011; pp. 32-33.

3. Huynh, L.; Beattie, D.A.; Fornasiero, D.; Ralston, J. Effect of polyphosphate and naphthalene sulfonate formaldehyde condensate on the rheological properties of dewatered tailings and cemented paste backfill. Miner. Eng. 2006, 19, 28-36. [CrossRef]

4. Dilling, P. Color Reduction Process for Non-sulfonated Lignin. U.S. Patent 4486346A, 4 December 1984.

5. Dilling, P. Lignosulfonate dispersants and the role of the reduction of azo dyes. Text. Chem. Col. 1986, 8, 17-24.

6. Liu, L.; Li, F.B.; Feng, C.H.; Li, X.Z. Microbial fuel cell with an azo-dye-feeding cathode. Appl. Microbiol. Biot. 2009, 85, 175-183. [CrossRef] [PubMed] 
7. Qiu, X.Q.; Yu, J.; Yang, D.J.; Wang, J.Y.; Mo, W.J.; Qian, Y. Whitening sulfonated alkali lignin via $\mathrm{H}_{2} \mathrm{O}_{2} / \mathrm{UV}$ radiation and its application as dye dispersant. ACS Sustain. Chem. Eng. 2017, 6, 1055-1060. [CrossRef]

8. Dilling, P.; Samaranayake, G.S. Mixtures of Amine Modified Lignin with Sulfonated Lignin for Disperse Dye. U.S. Patent 5989299A, 23 November 1999.

9. Yang, D.J.; Qiu, X.Q.; Pang, Y.X.; Zhou, M.S. Physicochemical properties of calcium lignosulfonate with different molecular weights as dispersant in aqueous suspension. J. Dispers. Sci. Technol. 2008, 29, 1296-1303. [CrossRef]

10. Lin, S.Y. Process for Reduction of Lignin Color. U.S. Patent 4184845A, 22 January 1980.

11. Qian, Y.; Zhong, X.; Li, Y.; Qiu, X.Q. Fabrication of uniform lignin colloidal spheres for developing natural broad-spectrum sunscreens with high sun protection factor. Ind. Crops Prod. 2017, 101, 54-60. [CrossRef]

12. Pu, Y.; Ragauskas, A.J. Structural analysis of acetylated hardwood lignins and their photoyellowing properties. Can. J. Chem. 2005, 83, 2132-2139. [CrossRef]

13. Zhang, H.; Yu, B.; Zhou, W.; Liu, X.; Chen, F. High-value utilization of eucalyptus kraft lignin: Preparation and characterization as efficient dye dispersant. Int. J. Biol. Macromol. 2018, 109, 1232-1238. [CrossRef] [PubMed]

14. Qin, Y.L.; Yang, D.J.; Guo, W.Y.; Qiu, X.Q. Investigation of grafted sulfonated alkali lignin polymer as dispersant in coal-water slurry. J. Ind. Eng. Chem. 2015, 27, 192-200. [CrossRef]

15. Yang, D.J.; Qiu, X.Q.; Zhou, M.S.; Lou, H.M. Properties of sodium lignosulfonate as dispersant of coal water slurry. Energ. Convers. Manag. 2007, 48, 2433-2438. [CrossRef]

16. Pang, Y.X.; Qiu, X.Q.; Yang, D.J.; Lou, H.M. Influence of oxidation, hydroxymethylation and sulfomethylation on the physicochemical properties of calcium lignosulfonate. Colloids Surf. A 2008, 312, 154-159. [CrossRef]

17. Park, K.M.; Yoon, I.; Lee, S.S.; Choi, G.; Lee, J.S. X-ray crystal structure of CI Disperse Blue 79. Dyes Pigments 2002, 54, 155-161. [CrossRef]

18. Geng, X.F.; Hu, X.Q.; Xia, J.J.; Jia, X.C. Synthesis and surface activities of a novel di-hydroxyl-sulfate-betaine-type zwitterionic gemini surfactants. Appl. Surf. Sci. 2013, 271, 284-290. [CrossRef]

19. Lou, H.M.; Lai, H.R.; Wang, M.X.; Pang, Y.X.; Yang, D.J.; Qiu, X.Q.; Wang, B.; Zhang, H.B. Preparation of lignin-based superplasticizer by graft sulfonation and investigation of the dispersive performance and mechanism in a cementitious system. Ind. Eng. Chem. Res. 2013, 52, 16101-16109. [CrossRef]

20. Sousa, F.D.; Reimann, A.; Jansson, M.B.; Nilberbrant, N. Estimating the amount of phenolic hydroxyl groups in lignins. In Proceedings of the 11th ISWPC, Nice, France, 11-14 June 2001; pp. 649-653.

21. Zhou, H.; Yang, D.; Qiu, X.; Wu, X.; Li, Y. A novel and efficient polymerization of lignosulfonates by horseradish peroxidase $/ \mathrm{H}_{2} \mathrm{O}_{2}$ incubation. Appl. Microbiol. Biot. 2013, 97, 10309-10320. [CrossRef] [PubMed]

22. Tejado, A.; Pena, C.; Labidi, J.; Echeverria, J.; Mondragon, I. Physico-chemical characterization of lignins from different sources for use in phenol-formaldehyde resin synthesis. Bioresour. Technol. 2007, 98, 1655-1663. [CrossRef] [PubMed]

23. Faix, O. Fourier transform infrared spectroscopy. In Methods in Lignin Chemistry; Lin, S.Y., Dence, C.W., Eds.; Springer: Berlin, Germany, 1992; pp. 83-109.

24. Song, Y.; Wang, Z.; Yan, N.; Zhang, R.; Li, J. Demethylation of wheat straw alkali lignin for application in phenol formaldehyde adhesives. Polymers 2016, 8, 209. [CrossRef]

25. Jahan, M.S.; Chowdhury, D.; Islam, M.K.; Moeiz, S. Characterization of lignin isolated from some nonwood available in Bangladesh. Bioresour. Technol. 2007, 98, 465-469. [CrossRef] [PubMed]

26. Bu, L.; Xing, Y.; Yu, H.; Gao, Y.; Jiang, J. Comparative study of sulfite pretreatments for robust enzymatic saccharification of corn cob residue. Biotechnol. Biofuels 2012, 5, 87. [CrossRef] [PubMed]

27. Hage, R.E.; Brosse, N.; Chrusciel, L.; Sanchez, C.; Sannigrahi, P.; Ragauskas, A. Characterization of milled wood lignin and ethanol organosolv lignin from miscanthus. Polym. Degrad. Stabil. 2009, 94, 1632-1639. [CrossRef]

28. .Gan, L.; Zhou, M.; Yang, D.; Qiu, X. Preparation and Evaluation of Carboxymethylated Lignin as Dispersant for Aqueous Graphite Suspension Using Turbiscan Lab Analyzer. J. Dispers. Sci. Technol. 2013, 34, 644-650. [CrossRef]

29. Hu, T. Characterization of Lignocellulosic Materials; Blackwell: Oxford, UK, 2009; pp. 68-71.

30. Lutnaes, B.F.; Myrvold, B.O.; Lauten, R.A.; Endeshaw, M.M. ${ }^{1} \mathrm{H}$ and ${ }^{13} \mathrm{C}$ NMR data of benzylsulfonic acids-model compounds for lignosulfonate. Magn. Reson. Chem. 2008, 46, 299-305. [CrossRef] [PubMed] 
31. Sakkayawong, N.; Thiravetyan, P.; Nakbanpote, W. Adsorption mechanism of synthetic reactive dye wastewater by chitosan. J. Colloid Interf. Sci. 2005, 286, 36-42. [CrossRef] [PubMed]

32. Zhang, L.; Gellerstedt, G. Quantitative 2D HSQC NMR determination of polymer structures by selecting suitable internal standard references. Magn. Reson. Chem. 2007, 45, 37-45. [CrossRef] [PubMed]

33. Willerich, I.; Li, Y.; Grohn, F. Influencing Particle Size and Stability of Ionic Dendrimer Dye Assemblies. J. Phys. Chem. B 2010, 114, 15466-15476. [CrossRef] [PubMed]

34. Kissa, E. Partitioning and stability of aqueous dispersions. Effect of electrolytes on the stability of aqueous dye dispersions. Langmuir 1990, 6, 1217-1221. [CrossRef]

35. Ujhelyiova, A.; Bolhova, E.; Oravkinova, J.; Tiňo, R.; Marcinčin, A. Kinetics of dyeing process of blend polypropylene/polyester fibres with disperse dye. Dyes Pigments 2007, 72, 212-216. [CrossRef]

(C) 2018 by the authors. Licensee MDPI, Basel, Switzerland. This article is an open access article distributed under the terms and conditions of the Creative Commons Attribution (CC BY) license (http:/ / creativecommons.org/licenses/by/4.0/). 